\title{
Meal-induced rise in resting energy expenditure in patients with complete cervical spinal cord lesions
}

\author{
A-K Aksnes Cand Scient, ${ }^{1} \mathrm{~T}$ Brundin MD ${ }^{2} \mathrm{~N}$ Hjeltnes MD,${ }^{1} \mathrm{~S}$ Maehlum MD ${ }^{1}$ \\ J Wahren MD $^{2}$ \\ ${ }^{1}$ Sunnaas Sykehus, 1450 Nesoddtangen, Norway; ${ }^{2}$ Department of Clinical Physiology, \\ Karolinska Hospital, Box 60500, S-10401 Stockholm, Sweden.
}

Central activation of the sympathoadrenal system is generally considered to be an essential component of the mechanisms whereby food ingestion stimulates resting energy expenditure. The functional importance of such sympathoadrenal stimulation has been demonstrated primarily in animals. To the extent that central sympathoadrenal stimulation is required for normal human nutrientinduced thermogenesis, this process should be defective in patients with complete cervical spinal cord lesion and severed connection between the central nervous system and the peripheral sympathetic nerves. Consequently, respiratory gas exchange was measured by indirect calorimetry in 9 tetraplegic patients and in 6 healthy individuals. Measurements were performed before and 2 hours after ingestion of a standardised mixed meal $(40 \%$ of basal $24 \mathrm{~h}$ energy requirements). The basal energy expenditure was $64 \pm 4$ watts in the tetraplegic patients and $79 \pm 6$ watts in the controls. After the meal, energy expenditure increased on average by $17 \pm 2$ watts or $26 \pm 3 \%$ of the basal values in the patients and by $14 \pm 2$ watts or $19 \pm 3 \%$ in the healthy controls (NS). The thermic effect of the meal, ie the rise in energy expenditure expressed in percent of the meal's energy content, was $5.5 \pm 0.7 \%$ in the patients and $3.8 \pm 0.6 \%$ in the controls (NS). Plasma concentrations of noradrenaline were low in the tetraplegic patients $(0.3-0.4 \mathrm{nmol} / \mathrm{l})$ compared to the healthy controls $(1.1-1.4 \mathrm{nmol} / 1), p<0.02$. It is concluded that nutrient-induced thermogenesis in tetraplegic patients with low sympathoadrenal activity is not diminished compared to healthy controls. The findings indicate that efferent sympathoadrenal stimulation from the brain is not a causal necessity for nutrient-induced thermogenesis in man.

Keywords: tetraplegia; energy expenditure; indirect calorimetry; sympathetic nervous system; insulin resistance.

\section{Introduction}

It is well known that food ingestion increases the metabolic rate to levels above basal. ${ }^{1-5}$ This phenomenon, referred to as nutrient-induced thermogenesis, starts within a few minutes, reaches its maximum after approximately $1 \mathrm{~h}$ and lasts for up to $6 \mathrm{~h}$ after food ingestion. The extra oxidative metabolism after meals is of quantitative importance for daily heat production and also, on a long term basis, for body weight homeostasis. The physiology of nutrientinduced thermogenesis has attracted clinical interest mainly because of its possible role in counteracting the development of obesity. In most obese individuals as well as in other conditions of insulin resistance, nutrientinduced thermogenesis is reduced below normal levels. ${ }^{6-11}$ However, the precise mechanisms whereby nutrients stimulate energy expenditure are not fully understood. Carbohydrate intake has been demonstrated to cause central stimulation of the sympathoadrenal system, a mechanism believed to contribute to nutrient-induced thermogenesis. ${ }^{12-17}$ On the other hand, 
protein is known to stimulate the metabolic rate far more effectively than carbohydrates and to do so without any measurable effect on the sympathoadrenal system. ${ }^{16,18,19}$ The aim of the present study was to assess the possible causal importance of central sympathoadrenal stimulation for the thermogenesis occurring in man after ingestion of a normal, mixed meal. Using indirect calorimetry, we measured the thermogenic response to a standardised, liquid, mixed meal in patients with complete cervical spinal cord injuries. Since in these patients contact between the central nervous system and the peripheral sympathetic nerves was severed, the anatomical prerequisite for central stimulation of the sympathoadrenal system was missing. ${ }^{20}$ The thermogenic response in the tetraplegic patients was compared with that obtained in healthy individuals after similar meals as well as with the response in a control group of tetraplegic patients receiving equal volumes of water instead of the meal.

\section{Methods}

\section{Subjects}

Seven male patients with chronic complete lesions of the cervical spinal cord and 6 healthy men participated in the study. The patients were consecutively admitted to the study. The first 6 patients received a mixed meal (group A) and the next 3 patients water (group B). Two of the patients participated in both groups. All the patients were examined clinically and neurologically and classified as Frankel class $\mathrm{A},{ }^{21}$ with injury levels between $\mathrm{C} 4$ and $\mathrm{C} 7$. Clinical and anthropometric data are given in Table I. All the patients had neuropathic bladders and used condom drainage, none had indwelling catheters. The tetraplegic patients had maintained steady bodyweight during the preceding 2 years. None of the patients had taken any medication on the day of the study. Otherwise, daily medication was for 2 patients in the meal group (A) and 2 in the control group (B) baclofen (Lioresal ${ }^{\circledR}$, CIBA-GEIGY) for muscle spasm prophylaxis. In addition, the 2 patients in group $B$ were on prazosin (Peripress ${ }^{\circledR}$, Pfizer) for urinary bladder control. All subjects were informed of the nature, purpose and possible risks of the study before giving their voluntary consent to participate. The study protocol was reviewed and approved by the institutional ethics committee.

\section{Methods}

The studies were performed in the morning after an overnight fast of $12-14 \mathrm{~h}$. An antecubital vein was cannulated for blood sampling. Expiration gas was collected by mouth-piece for measurements of ventilation and respiratory gas exchange using a pneumotachograph and paramagnetic and infrared analysers for oxygen and carbon dioxide, respectively (EOS Sprint, Jaeger, Würzburg, Germany). In the basal state expiration gas was collected for $30 \mathrm{~min}$. After the meal, gas was collected for $7 \mathrm{~min}$ at the end of every 15 min period during the $2 \mathrm{~h}$ postprandial study period. In the tetraplegic control group the gas collection was terminated at 90 min after the water ingestion. Venous blood samples were drawn before and every $15 \mathrm{~min}$ after the meal for determination of plasma concentrations of glucose, insulin and catecholamines. Blood glucose was determined by the glucose oxidase method. ${ }^{22}$ Plasma insulin levels were measured by radioimmunoassay, ${ }^{23}$ noradrenaline and adrenaline by HPLC and electrochemical detection. ${ }^{24}$ Heart rate was followed by continuous electrocardiogram recording (Cardiac Monitor 573, Kone, USA) and blood pressure was measured by sphygmomanometer technique every fifth min using an automatic blood pressure recorder (Paramed, model 9300, USA). Energy expenditure was calculated from the pulmonary gas exchange. ${ }^{25,26}$ The mixed meal was in liquid form $(600-700 \mathrm{ml})$, with an energy composition of $52 \%$ carbohydrate, $37 \%$ fat and $11 \%$ protein (Clinifeed $^{\circledR}$, Roussel Nutrition, France). The total energy content of the meal was set to $40 \%$ of the $24 \mathrm{~h}$ basal energy requirement, calculated from the individually basal energy expenditured, measured immediately prior to the meal. The tetraplegic control group received water only in volumes corresponding to the liquid meals given. 
Table I Clinical and anthropometric data for 9 male patients with complete cervical spinal cord injury (groups A and B) and 6 healthy male controls. Means \pm SEM

\begin{tabular}{|c|c|c|c|c|c|c|c|}
\hline & $\begin{array}{l}\text { Patient } \\
\text { number }\end{array}$ & $\begin{array}{l}\text { Injury } \\
\text { level }\end{array}$ & $\begin{array}{c}\text { Time since injury } \\
\text { (years) }\end{array}$ & $\begin{array}{l}\text { Age } \\
\text { (years) }\end{array}$ & $\begin{array}{l}\text { Height } \\
(\mathrm{m})\end{array}$ & $\begin{array}{l}\text { Weight } \\
\text { (kg) }\end{array}$ & $\begin{array}{c}\text { Basal metabolic rate } \\
\text { (watts) }\end{array}$ \\
\hline \multicolumn{8}{|l|}{ Tetraplegic patients } \\
\hline Group A $(n=6)$, meal & $1^{\mathrm{a}}$ & C6 & 1 & 23 & 1.87 & 66 & 57 \\
\hline & 2 & C6 & 6 & 27 & 1.85 & 71 & 79 \\
\hline & 3 & C6 & 1 & 21 & 1.80 & 74 & 63 \\
\hline & 4 & C6 & 11 & 30 & 1.88 & 72 & 57 \\
\hline & $5^{\mathrm{b}}$ & C6/7 & 4 & 34 & 1.81 & 62 & 64 \\
\hline & 6 & $\mathrm{C} 6$ & 5 & 26 & 1.79 & 64 & 66 \\
\hline Means \pm SEM & & & $5 \pm 2$ & $27 \pm 2$ & $1.83 \pm 0.2$ & $68 \pm 2$ & $64 \pm 4$ \\
\hline \multirow[t]{3}{*}{ Group B $(n=3)$, water } & 7 & C6/7 & 6 & 27 & 1.87 & 70 & 74 \\
\hline & 8 & C6/7 & 4 & 34 & 1.81 & 63 & 45 \\
\hline & 9 & $\mathrm{C} 6$ & 1 & 23 & 1.87 & 66 & 60 \\
\hline Mean \pm SEM & & & $4 \pm 1$ & $28 \pm 3$ & $1.85 \pm 0.2$ & $66 \pm 2$ & $59 \pm 8$ \\
\hline \multirow{7}{*}{$\begin{array}{l}\text { Healthy controls } \\
\qquad(n=6), \text { meal }\end{array}$} & & & & & & & \\
\hline & 10 & & & 18 & 1.73 & 55 & 80 \\
\hline & 11 & & & 23 & 1.81 & 74 & 81 \\
\hline & 12 & & & 22 & 1.88 & 80 & 83 \\
\hline & 13 & & & 30 & 1.80 & 62 & 77 \\
\hline & 14 & & & 30 & 1.80 & 84 & 72 \\
\hline & 15 & & & 21 & 1.80 & 66 & 80 \\
\hline Mean \pm SEM & & & & $24 \pm 2$ & $1.80 \pm 0.2$ & $70 \pm 5$ & $79 \pm 2$ \\
\hline
\end{tabular}

${ }^{\text {a }}$ same patient as no. 9 in group B

${ }^{\mathrm{b}}$ same patient as no. 8 in group $\mathrm{B}$ 
Statistics

Data were first analysed by repeated measures ANOVA. Differences between the groups were calculated by post hoc testing. ${ }^{27}$ Data in the text, tables and figures are expressed as mean \pm SEM.

\section{Results}

\section{Total oxygen uptake}

Total oxygen uptake in the basal state was $187 \pm 10 \mathrm{ml} / \mathrm{min}$ in the patients $(\mathrm{A}+\mathrm{B})$ and significantly lower $(p<0.01)$ than in the healthy subjects, $235 \pm 5 \mathrm{ml} / \mathrm{min}$. In response to the meal the oxygen uptake increased during the first $60 \mathrm{~min}$, after which it was essentially unchanged for the rest of the postprandial study period (Table II). In the patients (group A) the meal caused an average postprandial increase of $49 \pm 5 \mathrm{ml} / \mathrm{min}$ or $28 \pm 3 \%$ of basal. In the healthy subjects the corresponding values were $44 \pm 6 \mathrm{ml} / \mathrm{min}$ or $19 \pm 2 \%$ basal. The difference between the patients (A) and the healthy subjects did not attain statistical significance. In the patients (B) receiving water only, the postprandial oxygen consumption averaged $3 \pm 7 \mathrm{ml} / \mathrm{min}$ or $2 \pm 4 \%$ above the basal level.

\section{Respiratory exchange ratio}

Respiratory exchange ratio in the basal state was $0.83 \pm 0.02$ in the patient groups $(\mathrm{A}+\mathrm{B})$ and $0.86 \pm 0.04(\mathrm{NS})$ in the healthy subjects. In response to the mixed meal respiratory exchange ratio rose $(p<0.05)$ to a maximum level of $0.88 \pm 0.03$ after $90 \mathrm{~min}$ in the patient group A, indicating an increase in the rate of carbohydrate oxidation (Table II). In the healthy subjects the basal respiratory quotients were unexpectedly high and fell during the first $15 \mathrm{~min}$ after the meal. This was followed by a gradual rise to levels similar to those in the patients (A). The difference between the patients (A) and the healthy subjects did not attain statistical significance. In the patients (B) given water the respiratory exchange ratios tended to vary but remained low during the latter part of the study period.

\section{Energy expenditure}

Energy expenditure calculated from respiratory gas exchange was $65 \pm 5$ watts in the basal state in the patient group $(\mathrm{A}+\mathrm{B})$, significantly lower $(p<0.01)$ than in healthy subjects, $79 \pm 6$ watts. In relation to normal values calculated from body dimensions according to the equation of Harris and Benedict, ${ }^{28}$ the average energy expenditure in the patients groups $(\mathrm{A}+\mathrm{B})$ was $-20 \pm 3$ watts or $25 \pm 4 \%$ below the calculated basal level. For the healthy subjects the corresponding average deviation was $-7 \pm 4$ watts or $7 \pm 4 \%$ below the calculated basal values. The average postprandial energy expenditure in the patients (A) was $17 \pm 2$ watts or $26 \pm 3 \%$ above basal, in the healthy subjects $14 \pm 2$ watts or $18 \pm 3 \%$ above the observed basal level (NS) (Fig 1). The thermic effect of the meal, ie the increase in energy expenditure expressed in percent of the meal's energy content, was $5.5 \pm 0.7 \%$ in the patients (A) and $3.8 \pm 0.6 \%$ in the healthy controls (Fig 2). The difference was not statistically significant.

\section{Heart rate}

Heart rate in the basal state was $55 \pm 2$ beats/min in the patients $(A+B)$, and $64 \pm 2$ beats/min in the healthy subjects $(p<0.05)$. After the meal the heart rate rose significantly $(p<0.05)$, by an average of $6-7$ beats/min above basal levels, in both the patients (A) and the healthy subjects. In the patients (B) receiving water only, there was no postprandial increase in heart rate.

\section{Blood pressure}

Blood pressure was followed throughout the studies. In the basal state the systolic pressure was $108 \pm 5$ in the patients $(A+B)$ and $114 \pm 2$ in the healthy subjects. The corresponding diastolic values were $59 \pm 4$ and $67 \pm 3$. No significant postprandial changes occurred in either the systolic or the diastolic pressures.

\section{Venous blood glucose concentration}

Venous blood glucose concentration in the basal state was $3.9 \pm 0.1 \mathrm{mmol} / \mathrm{l}$ in the 
Table II Pulmonary oxygen uptake, respiratory exchange ratio, calculated energy expenditure and heart rate in the basal state and at timed intervals after ingestion of mixed meals corresponding to $40 \%$ of basal $24 \mathrm{~h}$ energy requirements given to 6 tetraplegic patient (group A) and 6 healthy control subjects. Three tetraplegic patients (group B) received corresponding volumes of water. Means \pm SEM

\begin{tabular}{|c|c|c|c|c|c|c|c|}
\hline & Basal & $15 \mathrm{~min}$ & $30 \mathrm{~min}$ & $45 \mathrm{~min}$ & $60 \mathrm{~min}$ & $90 \mathrm{~min}$ & $120 \mathrm{~min}$ \\
\hline \multicolumn{8}{|c|}{ Pulmonary $\mathrm{O}_{2}$-uptake (ml/min) } \\
\hline Tetraplegics A (meal) & $192 \pm 10$ & $215 \pm 19$ & $238 \pm 17$ & $247 \pm 14$ & $243 \pm 13$ & $247 \pm 15$ & $245 \pm 12$ \\
\hline Tetraplegics B (water) & $180 \pm 26$ & $170 \pm 23$ & $190 \pm 33$ & $170 \pm 23$ & $170 \pm 23$ & $190 \pm 15$ & - \\
\hline Healthy controls (meal) & $232 \pm 5$ & $240 \pm 7$ & $270 \pm 10$ & $278 \pm 8$ & $283 \pm 16$ & $285 \pm 18$ & $273 \pm 11$ \\
\hline \multicolumn{8}{|l|}{ Respiratory exchange ratio } \\
\hline Tetraplegics A & $0.81 \pm 0.02$ & $0.78 \pm 0.02$ & $0.84 \pm 0.01$ & $0.82 \pm 0.03$ & $0.86 \pm 0.03$ & $0.88 \pm 0.03$ & $0.86 \pm 0.04$ \\
\hline Tetraplegics B & $0.86 \pm 0.04$ & $0.81 \pm 0.01$ & $0.87 \pm 0.04$ & $0.83 \pm 0.02$ & $0.81 \pm 0.02$ & $0.80 \pm 0.03$ & - \\
\hline Healthy controls & $0.86 \pm 0.04$ & $0.79 \pm 0.02$ & $0.82 \pm 0.02$ & $0.84 \pm 0.03$ & $0.86 \pm 0.02$ & $0.86 \pm 0.02$ & $0.84 \pm 0.03$ \\
\hline \multicolumn{8}{|l|}{ Energy expenditure (watts) } \\
\hline Tetraplegics A & $64 \pm 4$ & $72 \pm 6$ & $81 \pm 6$ & $83 \pm 5$ & $83 \pm 5$ & $84 \pm 5$ & $83 \pm 4$ \\
\hline Tetraplegics B & $59 \pm 8$ & $56 \pm 8$ & $64 \pm 11$ & $56 \pm 8$ & $57 \pm 7$ & $64 \pm 5$ & - \\
\hline Healthy controls & $79 \pm 2$ & $80 \pm 3$ & $91 \pm 4$ & $94 \pm 3$ & $96 \pm 6$ & $97 \pm 6$ & $92 \pm 4$ \\
\hline \multicolumn{8}{|l|}{ Heart rate (beats/min) } \\
\hline Tetraplegics A & $57 \pm 3$ & $59 \pm 4$ & $70 \pm 5$ & $69 \pm 4$ & $61 \pm 3$ & $63 \pm 6$ & $67 \pm 6$ \\
\hline Tetraplegics B & $52 \pm 3$ & $48 \pm 3$ & $54 \pm 2$ & $51 \pm 2$ & $50 \pm 1$ & $51 \pm 4$ & - \\
\hline Healthy controls & $64 \pm 2$ & $67 \pm 3$ & $72 \pm 2$ & $70 \pm 3$ & $70 \pm 3$ & $72 \pm 4$ & $66 \pm 2$ \\
\hline
\end{tabular}




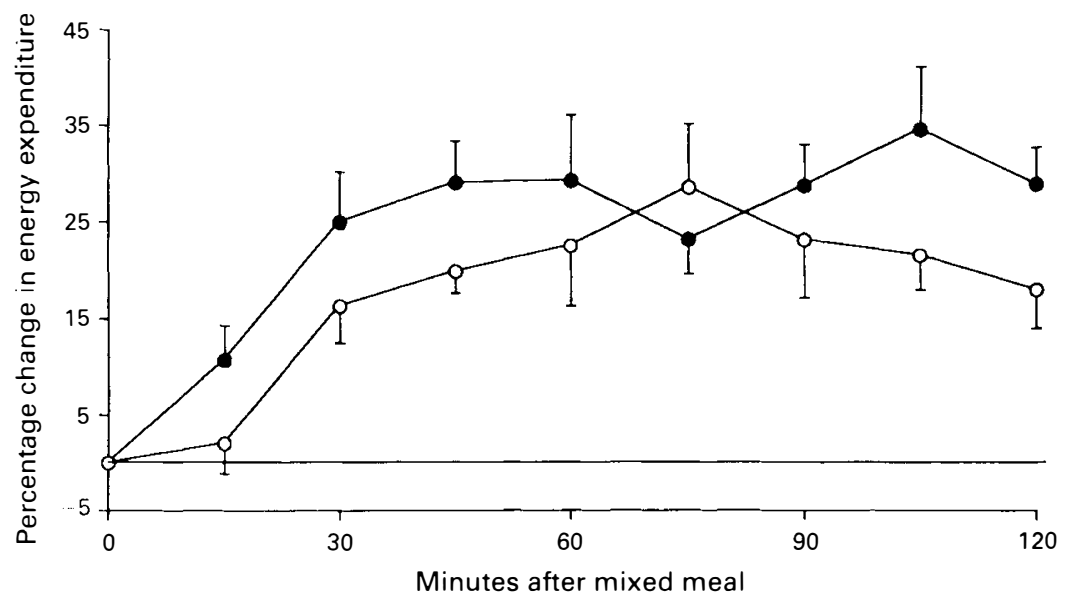

Figure 1 Changes in energy expenditure expressed in percent of basal, af ter ingestion of a mixed meal in 6 tetraplegic patient (solid symbols) and 6 healthy controls (open symbols). Means \pm SEM.

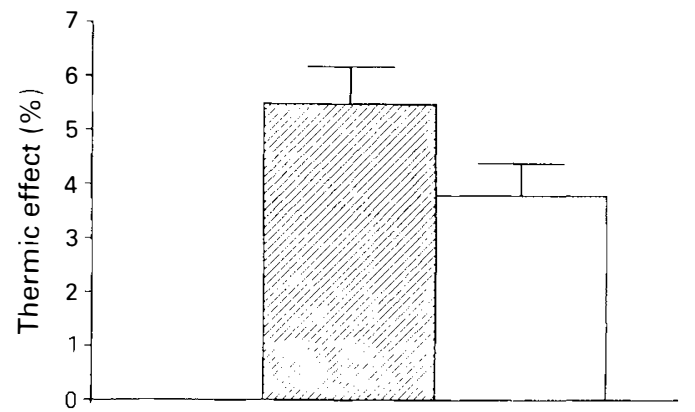

Figure 2 Thermic effect of a mixed meal in 6 tetraplegic patients (hatched column) and 6 healthy controls (open column). Mean \pm SEM. Thermic effect was calculated as the postprandial rise in energy expenditure expressed as percent of the meal's energy content.

patients $(\mathrm{A}+\mathrm{B})$ and $4.3 \pm 0.2$ in the healthy controls. The patients in group $\mathrm{A}$ had significantly lower basal values than the healthy subjects $(p<0.05)$, whereas group $\mathrm{B}$ had not. After the meal the blood glucose concentration rose gradually in both groups (Fig 3). In the patients (A) the initial rise was significantly higher $(p<0.05)$ than in the healthy subjects. In the patients the peak values were reached after $45 \mathrm{~min}$, in the healthy subjects after $30 \mathrm{~min}$. From 75 to $120 \mathrm{~min}$ after the meal the glucose levels were significantly higher in the patients $(p<0.05)$ than in the healthy subjects. The average postprandial rise in glucose concentration above basal was $1.7 \pm 0.2 \mathrm{mmol} / 1$ or $46 \pm 7 \%$ in the patients (A) and $0.4 \pm$ $0.3 \mathrm{mmol} / \mathrm{l}$ or $11 \pm 7 \%$ in the healthy subjects $(p<0.05)$. In the patients (B) receiving water, the glucose concentrations remained essentially unchanged during the postprandial study period.

\section{Plasma insulin}

Plasma insulin in the basal state was $6.5 \pm 0.8 \mathrm{mU} / \mathrm{l}$ in the patients $(\mathrm{A}+\mathrm{B})$ and $7.1 \pm 0.8 \mathrm{mU} / 1$ in the healthy subjects (NS) (Table III). During the first postprandial hour the insulin concentration rose by on average $61 \pm 8 \mathrm{mU} / 1$ in the patients (A) and $52 \pm 10 \mathrm{mU} / 1$ in the healthy controls $(p<0.05)$. During the second postprandial hour there were no significant differences between the patients (A) and the healthy subjects. No changes in plasma insulin concentrations were observed in the patients $(\mathrm{B})$ receiving water.

\section{Catecholamines}

In the basal state the blood concentration of noradrenaline in the patients $(\mathrm{A}+\mathrm{B})$ was $0.36 \pm 0.09 \mathrm{nmol} / 1$, significantly lower 


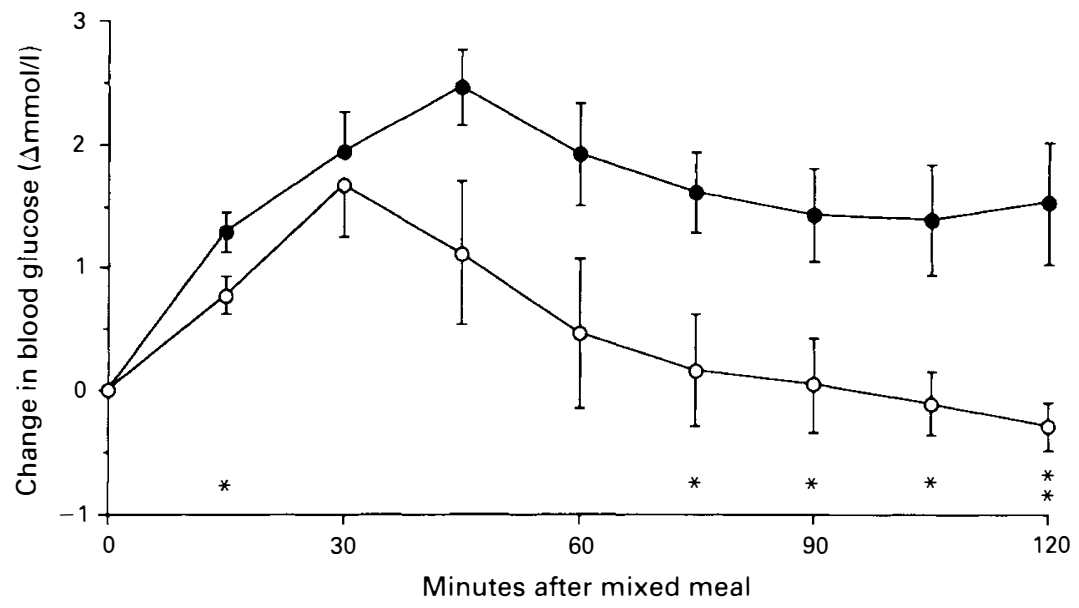

Figure 3 Changes in venous blood glucose concentration after ingestion of a mixed meal in 6 tetraplegic patients (solid symbols) and 6 healthy controls (open symbols). Means \pm SEM. *Indicates a statistically significant difference between the groups.

$(p<0.02)$ than in the healthy subjects, $1.05 \pm 0.20 \mathrm{nmol} / \mathrm{l}$. After the meal the noradrenaline concentrations showed a statistically insignificant tendency to increase in the healthy subjects, the highest postprandial values being $1.28 \pm 0.21 \mathrm{nmol} / 1$. In the patients, the plasma levels remained low and not significantly different from basal during the postprandial study period in both groups. The concentrations of adrenaline were below measurable levels in both the patients and the healthy subjects.

\section{Discussion}

The present results demonstrate that the rise in energy expenditure during the first $2 \mathrm{~h}$ after a standardised mixed meal is not diminished in patients with clinically complete lesions of the cervical spinal cord compared with healthy controls. In fact, the early phase of the thermic effect of the meal, ie the increase in energy expenditure expressed in percent of the meal's energy content, tended to be greater rather than smaller in the patients compared to the healthy controls (Fig 2). In this context it may be noted that a reduced lean body mass has been reported in tetraplegic patients. ${ }^{29}$ Body composition was not directly measured in the present study but the ratio between basal energy expenditure and body weight was approximately $14 \%$ lower in the patients than in the healthy controls (Table I, II). Since the basal energy expenditure is directly related to lean body mass ${ }^{30}$ in patients with tetraplegia, ${ }^{29,31}$ this finding indicates that the lean body mass was also significantly reduced in the present patients. Consequently, the thermic effect of the meal, when considered in relation to lean body mass, is likely to be greater in the patients than in the healthy controls.

Central activation of the sympathoadrenal system has been considered to be an essential component of the mechanism whereby nutrients stimulate the body's energy metabolism. In tetraplegic patients, however, the central activation of the sympathic nervous system is dissociated from cerebral regulation. The sympathoadrenal activity was very low in the patients, both in the basal state and after the mixed meal, as assessed from the plasma concentrations of cathecholamines. The patient's plasma noradrenaline levels were only one third of those in the healthy subjects and the adrenaline concentrations were below the level of detection. In addition, the patients showed no significant rise in noradrenaline concentrations in response to the meal. In the healthy subjects, noradrenaline levels tended to rise slightly but no significant 
Table III Venous blood concentrations of glucose and venous plasma concentrations of insulin and noradrenaline in the basal state and at timed intervals after ingestion of mixed meals corresponding to $40 \%$ of basal $24 \mathrm{~h}$ energy requirements given to 6 tetraplegic patients (group A) and 6 healthly control subjects. Three tetraplegic patients (group B) received corresponding volumes of water. Means \pm SEM

\begin{tabular}{|c|c|c|c|c|c|c|c|c|c|c|c|c|c|c|c|c|}
\hline \multirow{2}{*}{ Glucose $(\mathrm{mmol} / \mathrm{l})$} & \multicolumn{2}{|c|}{ Basal } & \multicolumn{2}{|c|}{$15 \mathrm{~min}$} & \multicolumn{2}{|c|}{$30 \mathrm{~min}$} & \multicolumn{3}{|c|}{$45 \mathrm{~min}$} & \multicolumn{2}{|c|}{$60 \mathrm{~min}$} & \multicolumn{3}{|c|}{$90 \mathrm{~min}$} & \multicolumn{2}{|c|}{$120 \mathrm{~min}$} \\
\hline & & & & & & & & & & & & & & & & \\
\hline Tetraplegics A (meal) & 3.8 & \pm 0.1 & 5.5 & \pm 0.3 & 5.7 & \pm 0.3 & 6.2 & \pm & 0.3 & 5.7 & \pm 0.4 & 5.2 & & 0.3 & 5.3 & \pm 0.5 \\
\hline Tetraplegics B (water) & 4.4 & \pm 0.2 & 4.1 & \pm 0.4 & 4.3 & \pm 0.3 & 4.0 & \pm & 0.0 & 4.1 & \pm 0.3 & 4.1 & \pm & 0.3 & & - \\
\hline Healthy control (meal) & 4.3 & \pm 0.2 & 5.1 & \pm 0.3 & 6.1 & \pm 0.5 & 5.4 & \pm & 0.5 & 4.8 & \pm 0.5 & 4.4 & \pm & 0.3 & 4.1 & \pm 0.2 \\
\hline \multicolumn{17}{|l|}{ Insulin $(\mathrm{mU} / \mathrm{l})$} \\
\hline Tetraplegics A & 6.9 & \pm 1.1 & 55 & \pm 8 & 83 & \pm 21 & 96 & \pm 2 & & 70 & \pm 10 & 47 & \pm 1 & & 56 & \pm 7 \\
\hline Tetraplegics B & 6.7 & \pm 1.1 & $5.6^{\mathrm{a}}$ & & 5.8 & \pm 1.2 & $4.9^{\mathrm{a}}$ & & & 5.5 & \pm 1.2 & $7.2^{\mathrm{a}}$ & & & & - \\
\hline Healthy control & 7.1 & \pm 0.8 & 31 & \pm 7 & 75 & \pm 17 & 83 & \pm & & 81 & \pm 25 & 47 & \pm 1 & & 35 & \pm 8 \\
\hline \multicolumn{17}{|l|}{ Noradrenalin (nmol/l) } \\
\hline Tetraplegics A & 0.33 & $3 \pm 0.12$ & 0.34 & \pm 0.15 & 0.42 & \pm 0.19 & 0.42 & \pm & 0.13 & 0.36 & \pm 0.18 & 0.40 & - & 0.18 & 0.26 & \pm 0.07 \\
\hline Tetraplegics B & 0.39 & \pm 0.15 & $0.46^{\mathrm{a}}$ & & 0.37 & \pm 0.14 & 0.53 & & & 0.34 & \pm 0.08 & $0.40^{\mathrm{a}}$ & & & & - \\
\hline Healthy controls & 1.05 & $5 \pm 0.20$ & 1.28 & \pm 0.21 & 1.12 & \pm 0.20 & 1.27 & \pm & 0.30 & 1.19 & \pm 0.22 & 1.10 & \pm & 0.15 & 1.12 & \pm 0.18 \\
\hline
\end{tabular}

a Mean values from only 2 of the patients. 
increments occurred in response to the meal. However, in larger study groups receiving mixed or carbohydrate-rich meals, significant noradrenaline increments have been reported. ${ }^{12,13,15-17}$

In many patients with tetraplegia due to cervical spinal cord lesions, episodes of so called autonomic dysreflexia may occur in respones to various stimuli (eg distension or emptying of the urinary bladder, distension of the bowels). ${ }^{21,32,33}$ During such episodes, manifested by elevated blood pressure, bradycardia, flushing and sweating, increased blood levels of catecholamines have been demonstrated indicating increased peripheral sympathetic nervous activity. ${ }^{32}$ The adrenergic receptor response to such episodes of activity in peripheral sympathetic nerves may be heightened by denervation supersensitivity. Consequently patients showing signs of autonomic dysreflexia were excluded from the present study. Two of the patients given water developed elevated body pressure, bradycardia and sweating in association with bladder emptying. Their results were not included in the study. None of the others showed clinical signs of autonomic dysreflexia during the course of the study. It is thus unlikely that local reflexogenic sympathetic activity contributed to the postprandial rise in energy expenditure. The finding of a substantial increase in energy expenditure after ingestion of a mixed meal in tetraplegic patients with no accompanying rise in sympathoadrenal activity runs counter to the view that central stimulation of the sympathetic nervous is of causal importance for the regulation of a significant proportion of nutrient-induced thermogenesis. ${ }^{12-15,17}$ However the mechanism behind the nutrient-induced thermogenesis is still incompletely understood. Recent studies have shown that the magnitude of the nutrientinduced thermogenesis may vary according to thermoregulatory requirements. Several studies have demonstrated a reduced thermogenic response in obese individuals. ${ }^{6-11}$ In addition, artificial thermal insulation of the abdominal wall in normal-weight subjects has been found to reduce the nutrientinduced thermogenesis to much the same extent as in the obese. The generation of heat was found to be depressed to such an extent that heat accumulation did not exceed the set point for the arterial blood temperature. ${ }^{6}$ These results have prompted the hypothesis that the nutrient-induced thermogenesis occurs primarily in peripheral tissues and may be reduced by inhibitory signals from the central nervous system, which are necessary to avoid hyperthermia in individuals in whom the conditions for normal heat dissipation are impaired (eg in obese individuals). ${ }^{6}$ It is not known by which mechanisms or neural tracts the thermoregulatory nuclei are able to reduce the whole-body heat production. It is possible, however, that this mechanism occurs via efferent neural signals from the central nervous system. Patients with cervical spinal cord lesions lack the anatomical basis for such inhibitory mechanisms. An increased nutrient-induced thermogenesis would then be expected in tetraplegic patients. Defective inhibition of peripheral heat production would also help explain why many tetraplegic patients are prone to develop hyperthermia in warm environments.

Several factors may have contributed to the small rise in heart rate that occurred after the meal in both the patients and the healthy controls. It may be secondary to reduced parasympathetic activity, to the increase in metabolic rate or, possibly, to the increase in blood temperature ${ }^{34}$ which occurs in response to food ingestion. ${ }^{6.35}$ Blood temperature was not monitored in the present study.

The basal blood concentration of glucose tended to be somewhat lower in the patients than in the controls. After the meal, blood glucose levels increased significantly more in the patients than in the healthy subjects. Along with glucose, the rise in the plasma concentration of insulin was significantly steeper in the patients than in the healthy controls. This finding confirms earlier observations of insulin resistance in tetraplegic patients. ${ }^{36.37}$ In this context it may be mentioned that insulin resistance has been proposed as one of the possible mechanisms that may reduce nutrient-induced thermogenesis in obese individuals and patients with diabetes type $2{ }^{38}$ However, the pres- 
ent results show that the insulin resistance that occurs in tetraplegic patients is not associated with a reduction of the thermic effect of food.

\section{References}

1 Jéquier E (1986) The influence of nutrient administration on energy expenditure in man. Clin Nutr 5: $181-186$.

2 Lusk G (1930) The specific dynamic action. J Nutrition 3: 519-530.

3 Rubner M (1885) Beiträge zur Lehre vom Kraftwechsel. I. Der Einfluss abundanter Kost auf die Wärmebildung. Sitzungs Berichte Königlich Bayerischen Akad Wiss 15: 452-461.

4 Rubner M (1894) Die Quelle der thierischen Wärme. Zschr Biologie 30: 73-142.

5 Rubner M (1902) Die Gesetze des Energieverbrauchs bei der Ernährung. Deuticker, Lepzig and Vienna.

6 Brundin T, Thörne A, Wahren J (1992) Heat leakage across the abdominal wall and meal-induced thermogenesis in normal-weight and obese subjects. Metabolism 41: 49-55.

7 Pittet P, Chappuis P, Acheson K. De Techtermann F, Jéquier E (1976) Thermic effect of glucose in obese subjects studied by direct and indirect calorimetry. Br J Nutr 35: 281-292.

8 Segal KR, Gutin B, Nyman $\AA$, Pi-Sunyer X (1985) Thermic effect of food at rest, during exercise, and after exercise in lean and obese men of similar body weight. J Clin Invest 76: 1107-1112.

9 Segal KR, Edaño A, Tomas MB (1990) Thermic effects of a meal over 3 and 6 hours in lean and obese men. Metabolism 39: 985-992.

10) Shetty PS, Jung RT, James WPT, Barrand MA. Callingham BA (1981) Postprandial thermogenesis in obesity. Clin Sci 60: 519-525.

11 Thörne A (1990) Diet-induced thermogenesis: An experimental study in healthy and obese individuals. Acta Chir Scand Suppl. 558. Thesis.

12 Astrup A, Simonsen L, Bülow J, Madsen J, Christensen NJ (1989) Epinephrine mediates facultative carbohydrate-induced thermogenesis in human skeletal muscle. Am J Physiol 257: E340-E345.

13 Berne C. Fagius J. Niklasson F (1989) Sympathetic response to oral carbohydrate administration. Evidence from microclectrode nerve recordings. J Clin Invest 84: 1403-1409.

14 Landsberg L, Young JB (1987) Fasting feeding and regulation of the sympathetic nervous system. $N$ Engl J Med 298: $1292-1301$

15 Welle SL, Lilavivat U, Campbell RG (1980) Increased plasma norepinephrine concentrations and metabolic rates following glucose ingestion in man. Metabolism 29: 806-809.

16 Welle SL, Lilavivat U, Campbell RG (1981) Thermic effect of feeding in man. Increased plasma norepinephrine levels following glucose but not protein or fat consumption. Metabolism 30: 953-958.

17 Young JB, Landsberg L (1977) Stimulation of sympathetic nervous system during sucrose feeding. Nature 269: $615-617$.

18 Karst H, Steiniger J, Noack R, Steglich HD (1984) Diet-induced thermogenesis in man: Thermic effects of single proteins, carbohydrate and fats depending on their energy amount. Ann Nutr Metab 28: 245-252.

19 Pittet P. Gygax PH, Jéquier E (1974) Thermic effect of glucose and amino acids in man studied by direct and indirect calorimetry. Br J Nutr 31: 343-349.

20) Wallin G, Stjernberg L (1984) Sympathetic activity in man after spinal injury. Brain 107: 183-198.

21 Frankel HL, Hancock DO, Hyslop G, Melzak J, Michaeli LS, Ungar GH et al (1969) The value of postural reduction in the initial management of closed injuries of the spine with paraplegia and tetraplegia. Paraplegia 7: 179-192.

22 Huggett ASG, Nixon DA (1957) Use of glucose oxidase, peroxidase and O-dianisidine in determination of blood and urinary glucose. Lancet ii: $368-370$.

23 Herbert V, Lau KS, Gottlieb CW, Bleicher SJ (1965) Coated charcoal immunoassay of insulin. J Clin Endocrin Metab 25: $1375-1384$.

24 Hjemdahl P, Odeskog H, Kahan T (1979) Determination of plasma catecholamines by high performance liquid chromatography with electrochemical detection; comparison with a radioenzymatic method. Life Sci 25: $131-138$

25 Lusk G (1924) Animal calorimetry. Twenty-fourth paper. Analysis of the oxidation of mixtures of carbohydrate and fat. A correction. J Biol Chem 59: 41-42.

26 Zunz N, Schumburg NAEF (1901) Studien zu einer Physiologie des Marsches, A. Hirshwald, Berlin.

27 Scheffé $\mathrm{H}$ (1953). A method for judging all contrasts in the analysis of variance. Biometrika 40: 87-104.

28 Harris JA, Benedict FG (1919) A biometric study of basal metabolism in man. Carnegie institution of Washington. Publication No 279.

29 Sedlock DA, Laventure SJ (1990) Body composition and resting energy expenditure in long term spinal cord injury. Paraplegia 28: 448-454.

30 Luke A, Schoeller DA (1992) Basal metabolic rate, fat-free mass, and body cell mass during energy restriction. Metabolism 41: 450-456.

31 Mollinger LA, Spurr GB, El Ghatit AZ, Barboriak JJ, Rooney CB, Davidoff DD et al (1985) Daily energy expenditure and basal metabolic rates of patients with spinal cord injury. Arch Phys Med Rehabil 66: 420-426. 
32 Mathias CJ, Christensen NJ, Corbett JL, Frankel HL, Spalding JMK (1976) Plasma catecholamines during paroxysmal neurogenic hypertension in quadriplegic man. Circ Res 39: 204-208.

33 Mathias CJ, Frankel HL (1983) Clinical manifestations of malfunctioning sympathetic mechanisms in tetraplegia. J Autonom Nerv Syst 7: 303-312.

34 Jose AD, Stitt F, Collison D (1970) The effects of exercise and changes in body temperature on the intrinsic heart rate in man. Am Heart J 79: 488-498.

35 Brundin T, Wahren J (1991) Influence of a mixed meal on splanchnic and interscapular energy expenditure in humans. Am J Physiol 260: E232-E237.

36 Corral RJM, Frier BM, McClemont EJW, Taylor SJ, Christie NE (1979-80) Recovery mechanisms from acute hypoglycaemia in complete tetraplegia. Paraplegia 17: 314-318.

37 Mathias CJ, Frankel HL, Turner RC, Christensen NJ (1979-80) Physiological responses to insulin hypoglycaemia in spinal man. Paraplegia 17: 319-326.

38 Felig P (1984) Insulin is the mediator of feeding-related thermogenesis: insulin resistance and/or deficiency results in a thermogenic defect which contributes to the pathogenesis of obesity. Clin Physiol 4: 267-273. 